\title{
Evaluation of Influence of Salt in the Cement Hydration to Oil Wells
}

\author{
Fernanda Rodrigues Lago ${ }^{a}$, Jardel Pereira Gonçalves ${ }^{b}$, Jo Dweck ${ }^{a}$, \\ Armando Lucas Cherem da Cunha ${ }^{\text {* }}$ \\ ${ }^{a}$ Departamento de Processos Inorgânicos, Universidade Federal do Rio de Janeiro, Centro de \\ Tecnologia, Bloco E, sala E-206, Cidade Universitária, RJ, Brazil \\ ${ }^{b}$ Universidade Federal da Bahia, Salvador, BA, Brazil
}

Received: January 17, 2017; Revised: November 10, 2017; Accepted: November 14, 2017

\begin{abstract}
The influence of $\mathrm{NaCl}$ salt in the hydration of the Portland cement paste class $\mathrm{G}$ was studied using a Non Conventional Differential Thermal Analysis (NCDTA) on the first 24 hours of cement hydration. The mass of salt used corresponds to $0,5,10,15$ and $20 \%$ of mass of water used in the preparation of the pastes. The water/cement ratio $(\mathrm{w} / \mathrm{c})$ remained constant, being 0.46 , and the pastes final volume was $99.9 \mathrm{~mL}$. Applying a deconvolution method to separate overlapped NCDTA peaks it was possible to estimate the energy released during the different stages of hydration and the effect of salt in cement hydration process. The presence of up to $10 \%$ of salt accelerated the hydration process and increased the hydration of $\mathrm{C}_{3} \mathrm{~S}$ and $\mathrm{C}_{3} \mathrm{~A}$, while the $20 \%$ of the salt causes a delayed hydration and decreased the hydration of $\mathrm{C}_{3} \mathrm{~S}$ and $\mathrm{C}_{3} \mathrm{~A}$. Futhermore, cement pastes with the same percentages of $\mathrm{NaCl}$ and with different hydration times were evaluated by Thermogravimetry (TG), Derivative Thermogravimetry (DTG) and Differential Thermal Analysis (DTA). After 28 days the presence of salt caused a greater increase in the formation of hydrated products.
\end{abstract}

Keywords: Cement hydration, $\mathrm{NaCl}, \mathrm{NCDTA}$, Thermal Analysis

\section{Introduction}

Cementing is one of the most important processes in the oil well drilling. However, when there is a flow of cement slurry in the annular of the well drilled in a saline zone, dissolution of the salts present in the rock by cement paste can occur, changing its physical properties among other effects, such as an acceleration or reduction of cement hydration. Therefore $\mathrm{NaCl}$ is applied on water used to prepare cement paste to mitigate dissolution in saline zone $e^{1,2,3}$.

Some authors concluded that low salt concentrations accelerate the hydration process and high salt concentrations retard the process ${ }^{1,3}$. The Friedel's salt formation in cement pastes containing $\mathrm{NaCl}$ is also reported ${ }^{1,4,12,13}$.

The thermal analysis has been used as a tool to analyze the products hydrated formed in cement pastes containing salts ${ }^{1,3,10}$. Rocha et al. ${ }^{1}$ concluded that there was a formation of Friedel's salt in the paste with $\mathrm{NaCl}$ due to reaction of ion $\mathrm{Cl}^{-}$with aluminate phase in cement class $\mathrm{G}$. The authors analyzed the hydrated phases by the mass loss on the thermogravimetry (TG) curves.

Some authors have been studying the influence of salt on cement paste hydration process ${ }^{1,2,3}$, however there are no studies in the literature that evaluate in real time the hydration process on the first 24 hours. In this period the highest reaction rate occurs.

*e-mail: armando@eq.ufrj.br
In this work, by Non Conventional Differential Thermal Analysis (NCDTA), the influence of $\mathrm{NaCl}$ in class $\mathrm{G}$ cement hydration process were evaluated in real time for the first 24 hours of process.

The NCDTA have been used to evaluate the effects of pozzolanic additions on the early stages of cement hydration ${ }^{5,8,11}$. In this technique external heat devices are not used and the system operates semi-adiabatically and the temperature difference between sample and reference can be measured due to thermal effects promoted by the exotermal reactions of cement hydration ${ }^{5,15}$.

The NCDTA curves represent the exothermal effects of a set of simultaneous reactions that occur during the hydration of cement to formdifferent products, which can be better understood if these simultaneous reactions were be studied separately. A technique for separating overlapped peaks obtained by NCDTA is the deconvolution, which was used in this paper. By this method it was possible to estimate the energy released during the different stages of cement hydration and the effect of salt in cement hydration process.

Beside the NCDTA technique, Thermogravimetric (TG), Derivative Thermogravimetric (DTG) and Differencial Thermal Analysis (DTA) were also used to evaluate the influence of $\mathrm{NaCl}$ salt in the hydration of cement paste. Finally, after 28 days of hydration, X-ray diffraction tests were performed on the pastes containing different percentages of salt. 


\section{Experimental}

\subsection{Materials}

In this study, a Brazilian Class G Portland cement was used, with a density of $3140 \mathrm{Kg} / \mathrm{m}^{3}$. This cement is developed for use in oil wells with high variation of pressure and temperature and with great depth. The product is manufactured with a special clinker of high resistance to sulfates. Its composition in oxides is shown in Table 1.

Table 1. Oxide percentages of the Class G Portland cement

\begin{tabular}{cc}
\hline Compound & Content (\%) \\
\hline $\mathrm{CaO}$ & 64.45 \\
$\mathrm{SiO}_{2}$ & 14.07 \\
$\mathrm{Fe}_{2} \mathrm{O}_{3}$ & 5.53 \\
$\mathrm{Al}_{2} \mathrm{O}_{3}$ & 4.11 \\
$\mathrm{SO}_{3}$ & 2.98 \\
$\mathrm{MgO}$ & 1.55 \\
$\mathrm{~K}_{2} \mathrm{O}$ & 0.05 \\
others & 5.31 \\
Loss on ignition & 1.95 \\
\hline
\end{tabular}

Deionized water and $\mathrm{NaCl}$, with a density of $2850 \mathrm{~kg} / \mathrm{m}^{3}$, also have been used in the sample preparation.

\subsection{Methods}

Class G Portland cement pastes were prepared following the appropriate percentage of each component in the mixture (cement + water + salt $)$. The water/cement ratio $(w / c)$ remained constant, being 0.46 , and the pastes final volume was $99.9 \mathrm{~mL}$. The salt was slowly solubilized in water utilized to prepare the paste. The mass of salt used corresponds to $0,5,10$, 15 and $20 \%$ of the mass of water used in the preparation of the pastes. This method was based on API Recommend Practice $^{6}$. The samples were named as reference, $5 \%, 10 \%$, $15 \%$ and $20 \%$ according to the percentage of salt contained.

In NCDTA procedures, cement pastes with $\mathrm{NaCl}$ percentage ranging from $0 \%$ (reference) to $20 \%$ were prepared as follows: the samples with different percentages of salt were placed in polypropylene cups inserted in expanded polystyrene support. The process promoting semi-adiabatic conditions. The supports were closed and the thermistors coupled to a temperature record interface were placed on the samples and centered to allow a more accurate temperature reading. All samples had the same initial temperature analysis. A schematics of the NCDTA used, is presented in Junior et al. ${ }^{15}$

The sample temperature datas $(\mathrm{Ta})$ were collected every 0.5 minutes performed by Vernier Software ${ }^{\mathrm{TM}}$. From these data it was possible to build a spreadsheet with the data as a

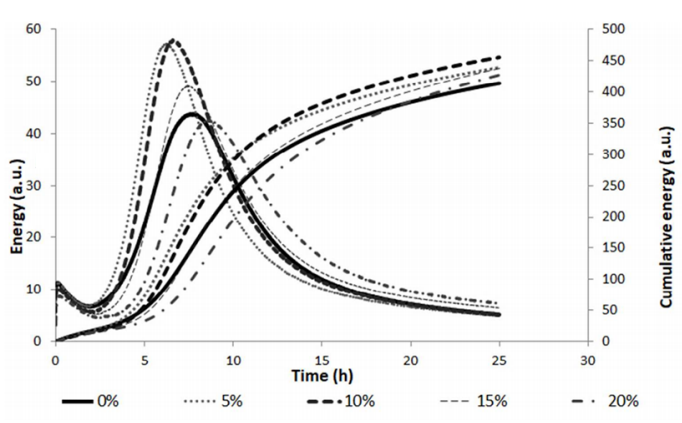

Figure 1. Normalized NCDTA curves and the respectives cumulative energy (arbitrary unity - a.u.) for samples with different percentages of $\mathrm{NaCl}$ in its hydration water.

function of time and obtain the NCDTA curve. The Ta was subtracted from the ambient temperature, collected from a thermistor present inside a cement sample already hydrated.

The NCDTA curves were normalized in relation to the weight of the materials used and their respective specific heats obtained by Differential Scanning Calorimetry (DSC), in the test temperature range.

To separate overlapped peaks obtained by normalized NCDTA, the deconvolution method was apllied by PeakFit ${ }^{\text {тM }}$ software Inc. ${ }^{7}$. A set of separated peaks is achieved, and a new NCDTA curve which presents the sum of separated peaks is drawn. The software compares the new curve with the original one to evaluate the effectiveness of the peak separation and allows one to choose the mathematical function which best fits with the new peak. In this article, the Gaussian function presented the best results. The area of each peak is proportional to the total heat generated by each reaction, being possible to evaluate the effect of the salt on the most important cement hydration reactions.

The analysis TG/DTG and DTA for 0, 5, 10, 15 and 20\% of $\mathrm{NaCl}$ dissolved in cement hydration water were analyzed after $1 \mathrm{~h}, 10 \mathrm{~h}, 24 \mathrm{~h}, 7$ days and 28 days of hydration. The samples were prepared with the same w/c ratio 0.46 . The paste analyses were performed in a TA Instrument, SDT Q600 model TG/DTA/DSC simultaneous apparatus with the same operating conditions as follows: heating hate of $10^{\circ} \mathrm{C} \mathrm{min}^{-1}$, from $35-1,000^{\circ} \mathrm{C}$, and using $100 \mathrm{~mL} \mathrm{~min}^{-1}$ of nitrogen flow. Before this, samples were dried inside the equipment initially at $1^{\circ} \mathrm{C} \mathrm{min}-1$ from ambient temperature to $35^{\circ} \mathrm{C}$, followed by a drying isothermal step at $35^{\circ} \mathrm{C}$ for $40 \mathrm{~min}$, to eliminate the free water. An effective way to calculate and compare the results is to consider the cement oxides in calcined cement mass. This method was introduced by Dweck et al, $2009^{9}$ and used in this article.

X-ray diffraction (XRD) analysis of the pasteswere taken using a BRUKER diffractometer, model D2 Phaser, and operating at $30 \mathrm{kV}$ and $10 \mathrm{~mA}$. Scans were performed with two theta range of $5-70^{\circ}$ with step increment of $0.03^{\circ} \mathrm{C} . \mathrm{s}^{-1}$. 


\section{Results and Discussion}

Figure 1 shows the normalized NCDTA curves of cement pastes containing $0,5,10,15$ and $20 \%$ of $\mathrm{NaCl}$ in respective hydration water. The normalized heat, in arbitrary units (a.u.) is due to the exothermal effect of cement hydration reactions in function of time.

By cumulative integration of the normalized NCDTA curves it was possible to obtain the cumulative energy curves of each sample in the first 24 hours of hydration as shown in Figure 1.

The first two hours of each NCDTA normalized curves represent the pre-induction and induction periods of cement hydration. This period is characterized by the hydration of Tricalcium Aluminate $\left(\mathrm{C}_{3} \mathrm{~A}\right)$ that in the presence of gypsum $\left(\mathrm{CaSO}_{4} \cdot 2 \mathrm{H}_{2} \mathrm{O}\right)$ generates ettringite $\left(\mathrm{C}_{3} \mathrm{~A} \cdot 3 \mathrm{CaSO}_{4} \cdot 32 \mathrm{H}_{2} \mathrm{O}\right)$. The ettringite is the most important AFt phase that represents a group of calcium sulfoaluminate hydrates. In the first hours of hydration there is no significant cumulutative energy difference between the samples and the reference.

The acceleration period in NCDTA curves corresponds to a time of hydration from the third to seventh hour and corresponds to the formation of $\mathrm{Ca}(\mathrm{OH})_{2}$ and gel of Tobermorite $(\mathrm{C}-\mathrm{S}-\mathrm{H})$ by Tricalcium Silicate $\left(\mathrm{C}_{3} \mathrm{~S}\right)$ hydration. This one corresponds to the second peak in Figure 1. The samples with lower salt content ( 5 and $10 \%$ ) showed a higher hydration rate compared to reference. We can see this effect better distinguished by the cumulative energy curves. It is possible to note that in this range, the sample with $20 \%$ of salt released less energy than the reference sample, since it presented a slightly lower second peak when compared to reference which lead to a lower $\mathrm{C}_{3} \mathrm{~S}$ hydration and lower formation of tobermorite.

It is also important to note that sample with $20 \%$ salt in its hydration water showed a maximum hydration rate after the reference one. For the $5 \%$ and $10 \%$ samples, the maximum rates of hydration occurred before the maximum rate of hydration of the reference, indicating an acceleration in the hydration of the cement in these cases. The sample containing $15 \%$ of $\mathrm{NaCl}$ in its hydration water did not show significantly difference when compared to reference, which may infer that the presence of this percentage of salt does not affect significantly cement hydration time under the experimental conditions tested.

These results agree with the ones obtained by Zhou et al. ${ }^{3}$ who evaluated the thickening time of cement slurries. The authors demonstrate that a low concentration $\mathrm{NaCl}$ exerts accelerating effect, resulting in short thickening time. However at higher concentration the effect of $\mathrm{NaCl}$ on the properties of the fresh slurries is reversed.

In order to a better understanding of the effects of salt in cement pastes, the PeakFit ${ }^{\mathrm{TM}}$ deconvolution method was applied in this paper to separate overlapped peaks from NCDTA curves, which are a consequence of simultaneous reactions that can occur in the early stages of cement hydration. Figures 2 and Figure 3 represent the typical plot of method for the reference and $20 \%$ sample respectively. The area of the first Gaussian peak is attributed to the heat generated by the hydration of $\mathrm{C}_{3} \mathrm{~A}$, since this is the first component to hydrate, forming ettringite. The second Gaussian peak occurs from 3-8 hours and is proportional to the heat generated by the hydration of the $\mathrm{C}_{3} \mathrm{~S}$, forming the $\mathrm{C}-\mathrm{S}-\mathrm{H}$ and $\mathrm{Ca}(\mathrm{OH})_{2}$.

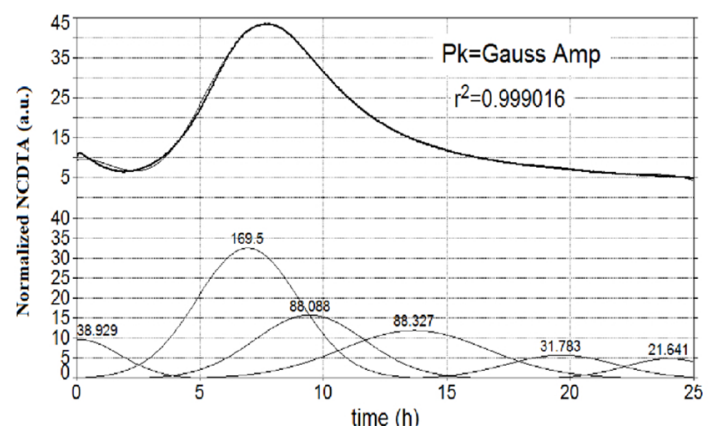

Figure 2. Deconvolution of reference sample.

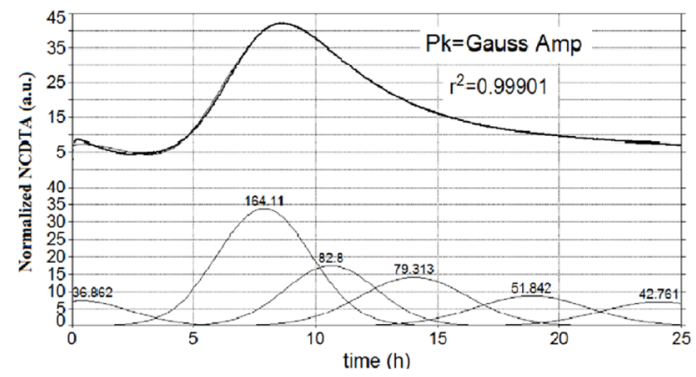

Figure 3. Deconvolution of sample with $20 \% \mathrm{NaCl}$ in its hydration water.

The curve situated at the top of the figures is the superimposition of the original curve and normalized NCDTA curve, representing the sum of the peak areas of Gaussian along the hydration time. The curves located at the bottom of the figures refer to the Gaussian peak areas generated with their respective areas in arbitrary units.

The third peak observed in the deconvolution may be assigned by Dicalcium Silicate $\left(\mathrm{C}_{2} \mathrm{~S}\right)$ hydration that occurs after hydration of $\mathrm{C}_{3} \mathrm{~S}$ and extends for a longer period of time. The other peaks are other products present in the clinker in lower percentage.

Figures 4 and Figure 5 represents a comparison of the areas of $\mathrm{C}_{3} \mathrm{~S}_{\text {and }} \mathrm{C}_{3} \mathrm{~A}$ hydration peaks for samples with 0,5 , 10,15 and $20 \%$ of $\mathrm{NaCl}$ in its hydration water. It is observed that pastes with $5 \%$ and $10 \%$ of salt present an increase in energy generated showing greater hydration of $\mathrm{C}_{3} \mathrm{~S}_{\text {and }} \mathrm{C}_{3} \mathrm{~A}$, in this time, and increased formation of C-S-H and ettringite. It is important to note that only after the deconvolution stage it was possible to verify the greater hydration of $\mathrm{C}_{3} \mathrm{~A}$.

The pastes with $20 \%$ of salt present a decrease in energy generated showing lower hydration of $\mathrm{C}_{3} \mathrm{~S}$ and $\mathrm{C}_{3} \mathrm{~A}$ and less 


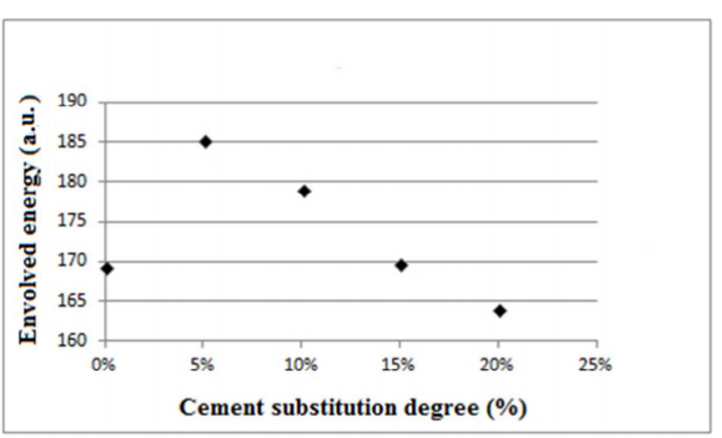

Figure 4. Envolved energy by samples with different percentage of $\mathrm{NaCl}$ in their hydration water for $\mathrm{C}_{3} \mathrm{~S}$ hydration.

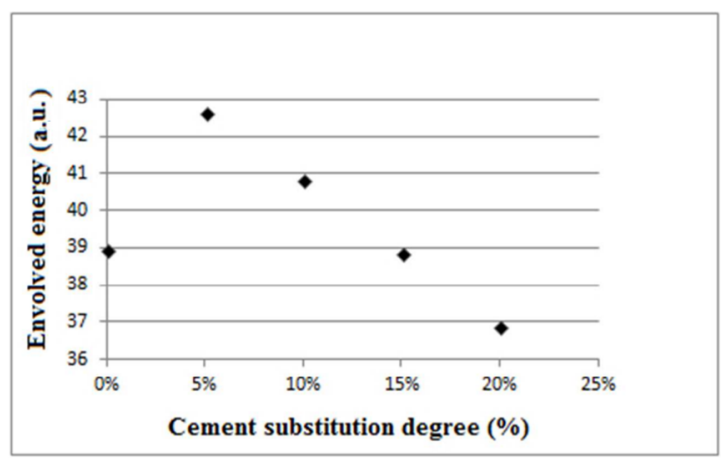

Figure 5. Envolved energy by samples with different percentage of $\mathrm{NaCl}$ in their hydration water for $\mathrm{C}_{3} \mathrm{~A}$ hydration.

formation of C-S-H and ettringite. The presence of $15 \%$ of $\mathrm{NaCl}$ did not presented significant energy release difference when compared to reference sample, indicating that the amount of salt in the paste did not affected significantly the hydration of cement under the experimental conditions tested.

For exemplifying purposes only, Figures 6 and Figure 7 show the curves of TG/DTG and DTA toreference, 5 and $20 \%$ samples. The first mass loss in $35^{\circ} \mathrm{C}$ were due to free water present in the samples. The determination of free water was possible due to the drying isothermal step realized as mentioned in Methods.

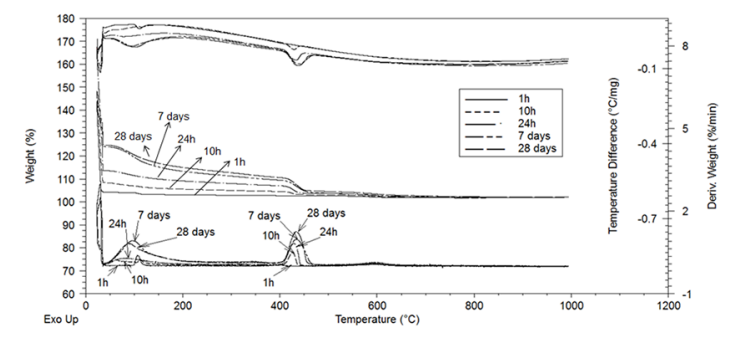

Figure 6. TG/DTG and DTA curves of reference.

In the samples analyzed after 10 hours of hydration between $35^{\circ} \mathrm{C}$ and $200^{\circ} \mathrm{C}$, we can observe a peak in the DTG curves related to the decomposition of the formed hydrated products such as C-S-H and ettringite.Besides that. in the

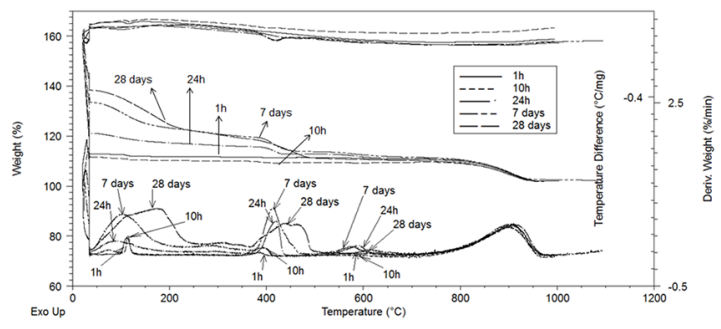

Figure 7. TG/DTG and DTA curves of sample with $20 \% \mathrm{NaCl}$ in its hydration water.

samples analyzed after 1 hour of hydration the loss mass also correspond to dehydration of gypsum still present.

The mass loss step from $350^{\circ} \mathrm{C}$ to $500^{\circ} \mathrm{C}$ is due to the decomposition of $\mathrm{Ca}(\mathrm{OH})_{2}$. It can be seen that the DTG peak from the second mass loss is quite small after 1hour of hydration for all samples, since $\mathrm{Ca}(\mathrm{OH})_{2}$ is not formed yet during the first hours of hydration. In samples with different percentages of $\mathrm{NaCl}$ after 28 days of hydration it is possible to observe peaks overlapped in the DTG curves between $350-500^{\circ} \mathrm{C}$, which indicates other products formed due to the presence of salt in the sample.

We can also see a mass loss in approximately $600^{\circ} \mathrm{C}$ on TG curves. This mass loss represents a decomposition of calcium carbonate $\left(\mathrm{CaCO}_{3}\right)$ indicating an initial process of samples carbonation because the contactof the air. The mass loss in $750-950^{\circ} \mathrm{C}$ represents the $\mathrm{NaCl}$ decomposition. That one is not present on cement sample without salt. In all cases, the corresponding endothermic phenomenas are observed in DTA curves.

In DTG curves it is possible to observe the overlapping of characteristic peaks due to thermal decomposition of tobermorite and ettringite, as well as in the samples containing higher percentages of salt where the peaks correspond to the decomposition of $\mathrm{Ca}(\mathrm{OH})_{2}$ and other products formed. Thus the percentage of total water combined was used to evaluate the percentages of hydration for each sample.

The Figure 8 shows the respectives mass loss of combined water from pastes with different salt's percentages. It is possible to observe an increase in the percentage of hydrated products for all samples analyzed up to 28 days of hydration. The presence of salt causes a greater increase in the formation of hydrated products in the evaluated period.

It is observed in Figure 8 that in the first day of hydration there is a greater percentage of combined water in the samples containing 5, 10 and $15 \%$ of salt. This result confirms the NCDTA and deconvolution assays show higher hydration energy of $\mathrm{C}_{3} \mathrm{~S}$ and $\mathrm{C}_{3} \mathrm{~A}$ for these samples. After seven days the samples containing higher percentages of salt have a higher reaction rate which is shown by the percentages observed in the TG/DTG analysis after 28 days of hydration.

To ilustrate, Figure 9 shows the x-ray diffraction patterns for the reference and $20 \%$ samples. In all samples containing salt it is possible to identify the presence of Friedel's salt 


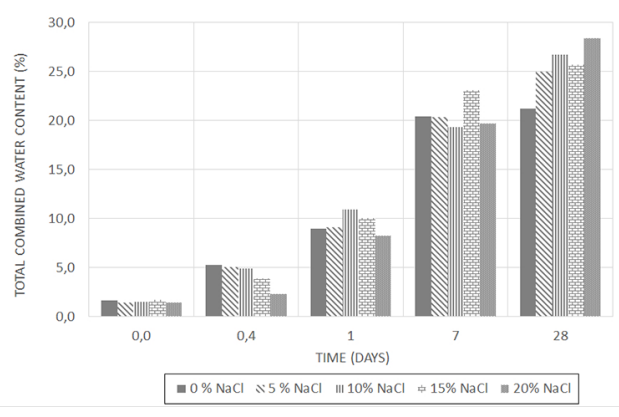

Figure 8. Total combinated water content for samples with different percentages of $\mathrm{NaCl}$ in its hydration water.

(FS). The presence of Friedel's salt justifies the overlapping of peaks found in the TG/ DTG analyzes between $350-500^{\circ} \mathrm{C}$. This result is in agreement with those found by Grischenko et al. ${ }^{14}$ who analyzed by TG/DTG, the thermal behavior of the FS and identified a loss of mass in the same temperature range corresponding to the release of water layers to form an amorphous product.

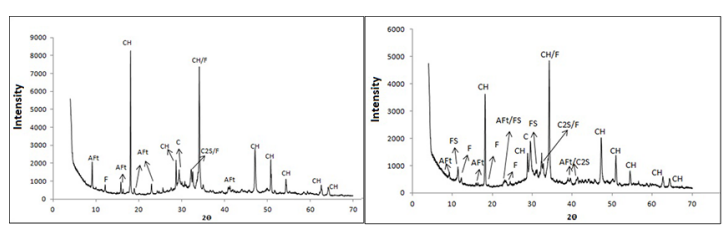

Figure 9. $\mathrm{X}$-ray diffraction patterns for the reference and $20 \%$ samples. $\mathrm{CH}\left(\mathrm{Ca}(\mathrm{OH})_{2}\right)$; AFt (ettringite); $\mathrm{F}\left(\mathrm{C}_{4} \mathrm{Af}\right) ; \mathrm{C}\left(\mathrm{CaCO}_{3}\right)$; FS (Friedel`s Salt).

\section{Conclusions}

In the 24 hours of the cement hydration process the presence of up to $10 \%$ of salt in hydration water accelerates the hydration process and increases the hydration of $\mathrm{C}_{3} \mathrm{~S}$ and $\mathrm{C}_{3} \mathrm{~A}$, while the $20 \%$ of the salt causes a delayed hydration and decreases the hydration of $\mathrm{C}_{3} \mathrm{~S}$ and $\mathrm{C}_{3} \mathrm{~A}$.

To better evaluate the hydration process of cement pastes containing salt dissolved in water, the percentage of total combined water obtained in the TG/DTG curves is the most appropriated due to the overlapping of peaks occurring during the thermal analysis.

In 28 days of the cement hydration process, the presence of salt in the water of hydration caused a greater increase in the formation of hydrated products due to Friedel salt formation.

\section{References}

1. Rocha CAA, Cordeiro GC, Toledo Filho RD. Use of thermal analysis to determine the hydration products of oil well cement pastes containing $\mathrm{NaCl}$ and $\mathrm{KCl}$. Journal of Thermal Analysis and Calorimetry. 2015;122(3):1279-1288.
2. Teodoriu C, Asamba P. Experimental study of salt content effect on class $\mathrm{G}$ cement properties with application to well integrity. Journal of Natural Gas Science and Engineering. 2015;24:324-329.

3. Zou X, Lin X, Huo M, Zang Y. The hydration of saline oil-well cement. Cement and Concrete Research. 1996;26(12):17531759 .

4. Lannegrand R, Ramos G, Talero R. Condition of knowledge about the Friedel's salt. Materiales de Construcción. 2001;51(262):6371.

5. Cunha ALC, Gonçalves JP, Bucher PM, Dweck J. Effect of metakaolin pozzolanic activity in the early stages of cement type II paste and mortar hydration. Journal of Thermal Analysis and Calorimetry. 2008;92(1):115-119.

6. IEEE. Standard: API RP 10B. Recommended Practice For Testing Well Cements. Lane Piscataway: IEEE; 1997.

7. SPSS Inc. PeakFit User's Manual. Chicago: SPSS Inc. Publication; 1997.

8. Dweck J, Ferreira da Silva PF, Aderne RS, Buchler PM, Cartledge FK. Evaluating cement hydration by non-conventional DTA; An Application to Waste Solidification. Journal of Thermal Analysis and Calorimetry. 2003;71(3):821-827.

9. Dweck J, Cunha ALC, Pinto CA, Goçalves JP, Bücher PM. Thermogravimetry on calcined mass basis-hydrated phases and pozzolanic activity quantitative analysis. Journal of Thermal Analysis and Calorimetry. 2009;97:85-89.

10. Pang X, Boul P, Jimenez WC. Isothermal calorimetry study of the effect of chloride accelerators on the hydration kinetics of oil well cement. Construction and Building Materials. 2015;77:260-269.

11. Neves Junior A, Lemos MS, Toledo Filho RD, Fairbair EMR, Dweck J. Early stages hydration of high initial strength Portland cement. Journal of Thermal Analysis and Calorimetry. 2013;113(2):659-665.

12. Talero R, Trusilewicz L. Morphological Differentiation and Crystal Growth Form of Friedel's Salt Originated from Pozzolan and Portland Cement. Industrial \& Engineering Chemistry Research. 2012;51(38):12517-12529.

13. Florea MVA, Browers HJH. Chloride binding related to hydration products: Part I: Ordinary Portland Cement. Cement and Concrete Research. 2012;42(2):282-290.

14. Grischenko RO, Emelina AL, Makarov PY. Thermodynamic properties and thermal behavior of Friedel's salt. Thermochimica Acta. 2013;570:74-79.

15. Neves Junior A, Viana MM, Dweck J, Toledo Filho RD. A Comparative Study Between the Early Stages Hydration of a High Strength and Sulphate Resistant Portland Cement and the Type II F Portland Cement Through Non Conventional Differential Thermal Analysis and Thermogravimetry. Materials Research. 2015;18(Suppl 2):291-296. 